\title{
The need for improved information exchange between family planning providers and clients
}

Population Council

Follow this and additional works at: https://knowledgecommons.popcouncil.org/departments_sbsr-rh

Part of the Demography, Population, and Ecology Commons, Family, Life Course, and Society Commons, International Public Health Commons, and the Women's Health Commons How does access to this work benefit you? Let us know!

\section{Recommended Citation}

"The need for improved information exchange between family planning providers and clients," Policy brief. Washington, DC: Population Council, 2017. 
The information exchanged during a contraceptive visit is important because providers need to understand clients' reproductive intentions and clients need to receive adequate information about the method options and possible method-related side effects and problems. Little is known about how information exchange has changed over time and across countries.

\section{BACKGROUND}

Achieving the " 120 by 20 " goal laid out by Family Planning 2020 (FP2020) requires not only helping never-users to initiate contraceptive use, but also reducing high contraceptive discontinuation among current users. The information exchange between family planning (FP) providers and clients is a critical component of reaching this goal. FP2020 has identified 17 core indicators to track progress made by FP programs. Among these is the Method Information Index (MII), which reflects some aspects of contraceptive information exchanged between providers and clients. The purpose of this study is to address the following issues: how the MII varies among countries, how it changes between two surveys in the same country, how it varies by type of method and women's characteristics, and whether any specific subgroups are responsible for observed changes in the MII between two surveys in a country.

\section{DATA AND METHODS}

The Population Council conducts research and delivers solutions that improve lives around the world. Big ideas supported by evidence: It's our model for global change. popcouncil.org
Data were drawn from the 25 countries for which the two most recent Demographic and Health Survey (DHS) -about five years apart-included the three questions needed to calculate the MII: "Were you

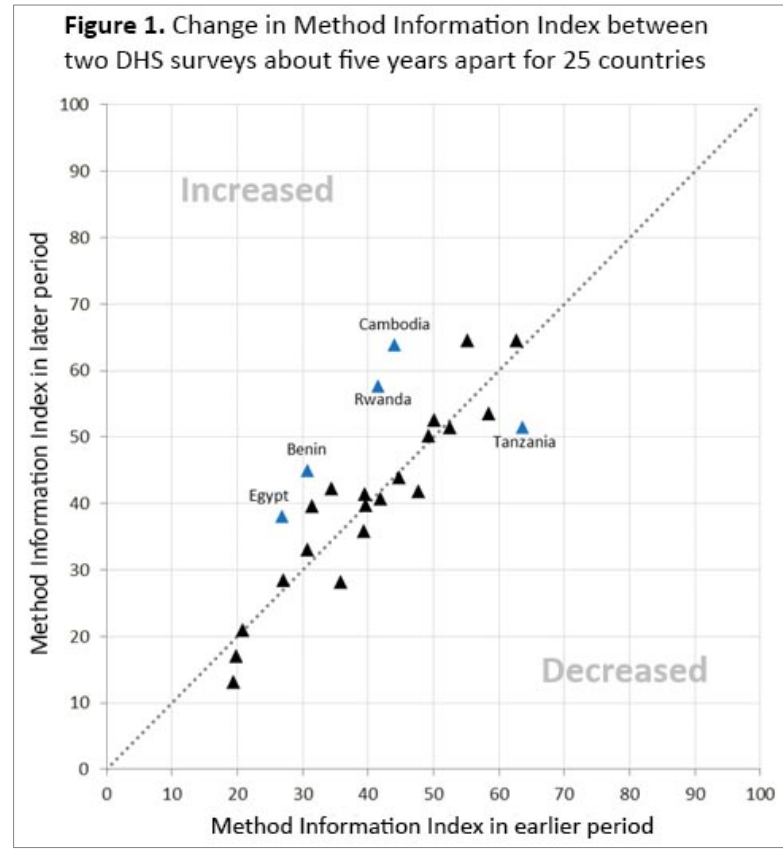

informed about other methods?" "Were you informed about side effects?" and "Were you told what to do if you experienced side effects?" The MII for a method is estimated by the proportion of current users of that method who responded "yes" to all three questions, in reference to what they had been told at the time they began use of their method within five years prior to the interview. The overall MII for all methods is the average of method-specific values, weighted by the proportion of users relying on a particular method. Data for each country can be found within the full report.

\section{RESULTS}

The weighted average MII for all countries at time 1 (2001-2008) was 34\%, which indicates that for the earlier survey, only about one-third of contraceptive users reported receiving adequate contraceptive information from their provider; the overall MII at time 2 (2006-2013) was about five percentage points 
higher (39\%). MII varies among regions and countries from 13\% in Pakistan to 65\% in Burkina Faso and Malawi at time $2 \mathrm{MII}$ increased in 15 countries and decreased in 10 (Figure 1). However, these changes in 14 countries were not statistically significant. As for country-level differences in the MII by method type, implant or IUD users in 23 out of 25 countries received the most information about their method which is still relatively low; women who relied on the pill or sterilization received the least. Results also indicate the median MII increased with household wealth (Figure 2). Similarly, the median MII increased with women's education, from $38 \%$ among women with no education to $54 \%$ among those with more than a secondary education. For all countries combined, the MII was greater for women who reported public-sector facilities rather than private-sector facilities as their source for contraceptives ( $47 \%$ vs. $36 \%$ ). Another study illustrates a detailed analysis of MII in India.

\section{DISCUSSION}

The results of this study suggest that although the concept of quality is widely accepted, many countries have made limited progress in providing adequate information to women adopting a contraceptive method. Moreover, the findings show that there is substantial room for improvement in all developing countries.

\section{COUNTRIES HAVE MADE LIMITED PROGRESS IN PROVIDING ADEQUATE INFORMATION TO WOMEN ADOPTING A CONTRACEPTIVE METHOD.}

Findings from this study also show that the MII and the MCPR are not correlated, which suggests that the two indicators reflect different aspects of FP programs. While the MCPR is the ratio of users to all married women of reproductive age, the MII is based on the information received by users only. A country focused on increasing its MCPR can do so with or without providing adequate information to users, as illustrated by comparing data from Ethiopia and Rwanda. Both of these sub-Saharan African countries experienced a rise in contraceptive prevalence between the two surveys, but the MII increased over time only in Rwanda. This suggests that the program in Rwanda may have focused on increasing contraceptive use and providing information to clients, whereas the program in Ethiopia may have focused only on the former. The two objectives are complementary, however, because adequate information exchange may reduce contraceptive discontinuation, which in turn will likely increase contraceptive prevalence over time.

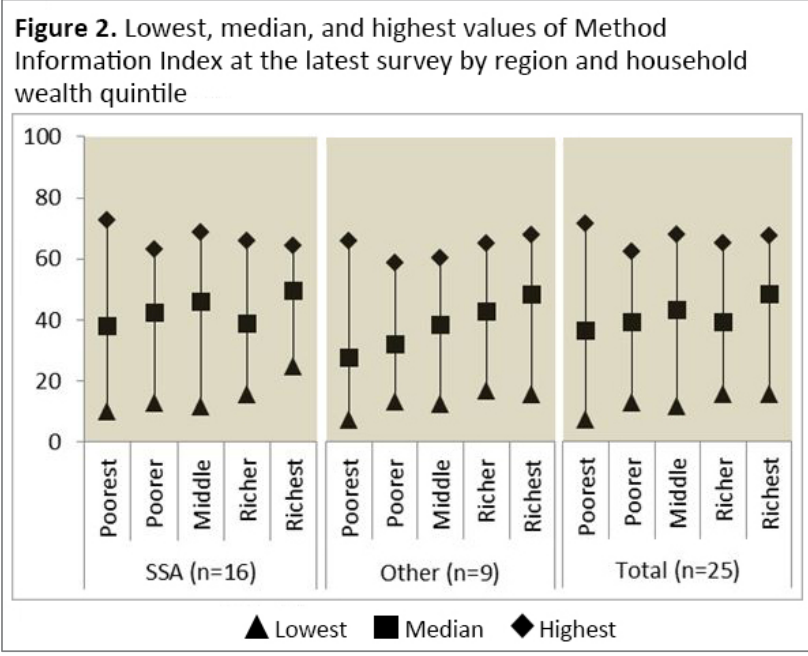

\section{CONCLUSION}

The results of this study show plenty of room to improve the content of information exchange, which could also result in quick wins in terms of better reproductive health outcomes among clients. Monitoring changes in the MII is important, but it is not enough. The index is unlikely to rise rapidly in the absence of special efforts by FP programs to improve the quality of care at service facilities, as well as in communities, among depot holders and at pharmacies offering resupply of methods. Concerted efforts are needed to improve the content of information exchange and quality of care. Studies in Pakistan and the Philippines have demonstrated that it is feasible to develop and implement interventions to train service providers in interacting with their clients to improve quality of care, and that the nature of client-provider interactions can be improved through these training interventions.

There may be some tension between achieving a numerical goal-such as reaching a certain number of modern contraceptive users-and improving the quality of services. A focus on achieving a numerical goal may adversely affect the quality of care provided in some countries. One way to minimize the potential conflict between quantity and quality is to include activities and budget to improve the content of information exchange in the country plans being articulated under the auspices of FP2020. Both the numerical goal and quality of care can be incorporated by setting the overall goal as " 120 by 20 through quality."

\footnotetext{
This brief is based on the article, Examining progress and equity in information received by women using a modern method in 25 developing countries, prepared by Anrudh K. Jain for the Measuring and Monitoring Quality of Services and Quality of Care project funded by a grant from the David and Lucile Packard Foundation to the Population Council. We gratefully acknowledge the support of the Foundation to continue research on the state of quality of care and the communications support of Katie Unthank in preparation of this brief.
} 